Archives de sciences sociales des religions

148 | octobre-décembre 2009

Bulletin Bibliographique

\title{
Le renouveau du Bulletin bibliographique des Archives
}

\section{L'équipe de rédaction}

\section{OpenEdition}

1 Journals

\section{Édition électronique}

URL : http://journals.openedition.org/assr/21484

DOI : $10.4000 /$ assr.21484

ISSN : $1777-5825$

Éditeur

Éditions de l'EHESS

\section{Édition imprimée}

Date de publication : 31 décembre 2009

Pagination : 73-74

ISBN : 978-2-7132-2218-4

ISSN : 0335-5985

Référence électronique

L'équipe de rédaction, "Le renouveau du Bulletin bibliographique des Archives ", Archives de sciences sociales des religions [En ligne], 148 | octobre-décembre 2009, mis en ligne le 09 février 2010, consulté le 21 septembre 2020. URL : http://journals.openedition.org/assr/21484 ; DOI : https://doi.org/ 10.4000/assr.21484

Ce document a été généré automatiquement le 21 septembre 2020.

(c) Archives de sciences sociales des religions 


\title{
Le renouveau du Bulletin bibliographique des Archives
}

\author{
L'équipe de rédaction
}

1 La rédaction des ASSR reste attachée à l'esprit du Bulletin Bibliographique qui a marqué la naissance de cette revue, et c'est bien dans cet esprit que nous avons souhaité garder le titre Archives de Sciences Sociales des Religions. La collaboration bénévole et régulière d'un collège invisible de lecteurs, recenseurs et auteurs de notes critiques est une richesse inestimable. Nos fondateurs considéraient que l'exercice du compte rendu de lecture est un moment essentiel dans la formation doctorale des jeunes chercheurs et une contribution attendue de tous à la vie de notre communauté scientifique.

2 L'entrée des ASSR dans le monde de l'édition commerciale a conduit de longue date le comité de rédaction à rechercher la manière la plus appropriée de maintenir l'éveil de l'esprit du BB. La vente au numéro autant que le souci de l'affichage de la ligne éditoriale de la revue imposent de donner la priorité sur quatre numéros par an à des numéros thématiques et à des varias. Le classement par ordre alphabétique des recensions reste lié néanmoins à l'idée première d'un parcours sinon exhaustif du moins aléatoire du champ d'étude qui offre des chemins de traverse mais qui n'est pas d'emblée commandé par les intérêts spécialisés des lecteurs et les «moteurs de recherche». Depuis plusieurs années, le BB est néanmoins toujours associé soit à des notes critiques, particulièrement appréciées et recherchées, soit à des varia qui diversifient la présentation et la lecture des numéros.

3 L'entrée dans l'édition électronique nous a conduits à pratiquer la mise en ligne gratuite des comptes rendus et notes critiques sur revues.org en dehors des contraintes de la barrière «flottante» de trois ans à laquelle sont soumis les articles de varia ou de numéros thématiques. Pour la période à venir, nous continuerons à mettre en ligne sur notre site revues.org, au rythme semestriel (juin/décembre) qui est celui des échéances du Bulletin Bibliographique, les comptes rendus parvenus dans les délais fixés, avec le souci d'encourager les auteurs de recensions à maintenir le rythme. Par contre, un «vrai» $B B$ en édition papier regroupant toutes les recensions et notes critiques de 
l'année sera réservé aux abonnés et ouvert à la vente au numéro une fois par an, en fin d'année.

4 Cette formule que nous inaugurons avec ce numéro nous semble la meilleure façon de renouer avec l'esprit originel du $\mathrm{BB}$, celui d'un état des lieux régulier des publications significatives de notre champ d'étude. À terme, cet esprit devrait se prolonger par la création d'un site web de veille éditoriale des ASSR créé et alimenté sur le portail de revues.org. Nul doute que les pionniers de la revue n'auraient pas hésité à investir ce nouvel outil pour faire rebondir leur projet initial.

5 En comptant sur votre fidélité dans cette nouvelle étape de l'histoire de la revue des ASSR.

\section{AUTEUR}

\section{L'ÉQUIPE DE RÉDACTION}

